\title{
Effects of Microwave Pre-treatment on the Quality of Kenaf (Hibiscus cannabinus L.) Seed Oil
}

\author{
Kar-Lin Nyam and Hui-Wan Lau \\ Department of Food Science and Nutrition, Faculty of Applied Sciences, UCSI University, Kuala Lumpur 56000, Malaysia
}

\begin{abstract}
The main aim of this study was to explore the effects of microwave pre-treatment on quality of kenaf seed oil by observing the changes in oil yield, oxidative stability, fatty acid components, tocopherols, antioxidant activities and color intensity of kenaf seed oil. Microwave pre-treatment on kenaf seeds did affect the quality of the extracted oils. Microwave pre-treatment increased the extracted oil yields significantly $(P<0.05)$. Moreover, the roasted oils showed a significant increase in oxidative stability, antioxidant stability and colour of kenaf seed oils. In terms of fatty acids composition, microwave roasting had greater effect on oleic acids (C18:1) and linoleic acids (C18:2), as roasting increased the oleic acid content but decreased linoleic acid. There was no significant difference in the palmitic acids $(\mathrm{C} 16: 0)$ and stearic acids $(\mathrm{C} 18: 0)(P>0.05)$. A significant decrease $(P<0.05)$ in the iodine value of the oils was found. In conclusion, kenaf seed oil roasted for $2 \mathrm{~min}$ had better oil quality if compared to the unroasted oil, as microwave pre-treatment improved the oil yield, oxidative stability and antioxidant activities of kenaf seed oil.
\end{abstract}

Key words: Fatty acid composition, tocopherol, antioxidant activity, oxidative stability, oil yield.

\section{Introduction}

Kenaf (Hibiscus cannabinus L.) is an annual, non-wood fiber plant native to East-Central Africa, where it has been grown for several thousand years for food and fibre [1]. The function of kenaf plant has been reported as traditional medicine to ease various symptoms and treat diseases, such as bruises and fever [2]. Kenaf seed oil contains fatty acids, phospholipids, and sterols [3]. Kenaf seed oil is high in unsaturated fatty acids (20.1\%-45.9\%) with linoleic, oleic and palmitic acids being predominant fatty acid in the oil [4]. The presence of high amount of linoleic acid in kenaf seed oil caused that the oil could be used as a good source of essential fatty acid [5]. The high percentage of oleic acid in oil makes it desirable in terms of nutrition and high stability as cooking and frying oil. Furthermore, many studies had shown that kenaf seed oil has high potential as edible oil, due to its relatively high oil content and the unique fatty acid

Corresponding author: Kar-Lin Nyam, assistant professor, research field: oil chemistry and technology. E-mail: nyamk1@ucsiuniversity.edu.my. composition which is similar to cottonseed oil [4]. Besides, tocopherols were reported to be found in kenaf seed oil. Tocopherols can act as biological antioxidant and have been coupled with the reduction of heart disease, delay of Alzheimer's disease and prevention of cancer [5].

Studies have shown that oils that undergo microwave pre-treatment will have better quality in terms of physicochemical properties, such as p-anisidine value, colour and smell [6]. Microwave pre-treatment provides a potential to induce stress reactions in plant systems and thus cause the cell membrane of oil seeds to rupture. Studies have shown that pre-treatment of hazelnuts with microwaves can increase the oil extraction yield, and increasing the treatment time also had a positive effect on the oil extraction yield [7]. In addition, microwaves heat treatment caused changes in composition and oxidative stability of the oils [8]. Microwave roasted rapeseed oils showed a markedly improved oxidative stability due to the increase of phenolic antioxidants [9]. The main aim of this research was to study the 
effects of microwave pre-treatment on the physico-chemical properties, antioxidant activities and the quality of the microwave pre-treated kenaf seed oil.

\section{Materials and Methods}

\subsection{Materials}

Kenaf (Hibiscus cannabinus L.) seeds were obtained from Malaysia Agricultural Research and Development Institute (MARDI), Selangor, Malaysia.

\subsection{Methods}

\subsubsection{Microwave Roasting of Kenaf Seeds}

Kenaf seeds were placed in Pyrex petri dishes (100 $\mathrm{g}$ in each petri dish) and were roasted in a consumer model microwave oven (Model: R-397J(S), SHARP, Malaysia) for 1, 2 and 3 min under power 1,100 W. Kenaf seeds were then allowed to cool to the ambient temperature and grinded into powder form by using grinder (Model: BL1111AD, Tefal, Indonesia). The particle size of kenaf seed powder was approximately $1 \mathrm{~mm}$.

\subsubsection{Kenaf Seed Oil Extraction}

The oils were extracted from the seeds with Soxhlet extractor using hexane at $60{ }^{\circ} \mathrm{C}$ for $3 \mathrm{~h}$. The oil was then recovered by evaporating off the solvent using rotary evaporator (Model: N-1, Eyela, Tokyo Rikakikal Co., Ltd., Japan), and residual solvent was removed by flushing with $99.9 \%$ nitrogen.

\subsubsection{Oil Yield}

Oil yield of kenaf seed oil was determined according to the method of Ref. [5] with slight modifications. Firstly, the round bottom flask containing the oil sample was cooled and weighed after hexane was removed. The oil yield was calculated based on the Eq. (1):

$$
\text { Oil yield }=\frac{\text { amount of extracted oil }}{\text { amount of kenaf seed used }} \times 100
$$

\subsubsection{Chemical Analysis}

The peroxide value $(P V), \mathrm{p}$-anisidine value $(A V)$, iodine value $(I V)$ and free fatty acid value (FFA) of all kenaf seed oil samples were determined as the method of Ref. [10].

The total oxidation values (TOTOX) of all kenaf seed oil samples were calculated from the $P V \mathrm{~s}$ and $A V \mathrm{~s}$ of the oil samples using Eq. (2), which was adapted from Ref. [11]:

$$
\text { TOTOX }=2 P V+A V
$$

2.2.5 Instrumental Analysis

(1) Fatty acid composition: analysis of fatty acid composition was done by the method adapted from Ref. [12].

(2) Tocopherols: analysis of tocopherols was done by the method adapted from Ref. [12].

\subsubsection{Antioxidant Activities}

(1) 1,1-diphenyl-2-picrylhydrazyl (DPPH) radical scavenging capacity assay: kenaf seed oil was determined by using DPPH radical scavenging capacity assay according to Ref. [13].

(2) Total phenolic content (TPC): analysis of total phenolic content in kenaf seed oil was done according to the method of Ref. [14]. The concentrations were calculated according to the standard equation:

$$
y=0.515 x+0.0055\left(R^{2}=0.9885\right)
$$

where, $y=$ absorbance; $x=$ concentration (mg of gallic $\mathrm{acid} / 100 \mathrm{~g}$ of kenaf seed oil); $R^{2}=$ correlation of determination.

(3) Total flavonoid content (TFC): total flavonoid content of kenaf seed oil was measured using a colorimetric assay in accordance with the method of Ref. [15]. The concentrations were calculated according to the standard equation:

$$
y=0.8225 x+0.0092\left(R^{2}=0.9896\right)
$$

where, $y=$ absorbance; $x=$ concentration ( $\mathrm{mg}$ of catechin $/ 100 \mathrm{~g}$ of kenaf seed oil); $R^{2}=$ correlation of determination.

\subsubsection{Colour Intensity}

Analysis of oil intensity was done by the method adapted from Ref. [16]. The colour of kenaf seed oil was measured using CIE Hunter Lab system (ColorFlex EZ Spectrophotometer, Hunter Associates Laboratory Inc., USA). Kenaf oil samples were 
subjected to measure the colour in term of $L^{*}$ (lightness), $a^{*}$ (redness) and $b^{*}$ (yellowness). The data for $L^{*}, a^{*}$ and $b^{*}$ of each sample was recorded.

\subsection{Statistical Analysis}

All experiments were performed in duplicate, and the measurements were replicated two times. Results were analyzed by using Minitab 16.2.3 software. All values were expressed as mean \pm standard deviation (SD). Paired student's $t$-test and one-way analysis of variance (ANOVA) were conducted, and the average values were compared with Fisher's multiple comparison test to determine significant differences $(P<0.05)$.

\section{Results and Discussion}

\subsection{Oil Yield}

The oil from kenaf seed roasted with different microwave roasting time was obtained by Soxhlet extraction. The yield of oil obtained for each sample was calculated (Table 1). Oil yields varied over a small range of $20.17 \%-22.05 \%$ among the samples. The highest yield was obtained from kenaf seed that roasted for $2 \mathrm{~min}(22.05 \%$ ), followed by $1 \mathrm{~min}$ (20.42\%), $0 \mathrm{~min}(20.37 \%)$ and $3 \mathrm{~min}(20.17 \%)$, respectively. The yields of kenaf seed oil showed an increment when the treatment time increased until 2 $\mathrm{min}$, and started to decrease when roasted for $3 \mathrm{~min}$. There was significant different $(P<0.05)$ among the four samples.

The yield of kenaf seed oil increased until the microwave pre-treatment time of $2 \mathrm{~min}$. It provides a potential to induce stress reactions in plant systems or oil seeds. By using microwave radiation in oil seeds, a higher extraction yield and an increase in mass transfer coefficients can be obtained, because the cell membrane is ruptured. Besides, more oil can be extracted from seed, as the permanent pores which are generated by microwaves heating enable the oil to move through the permeable cell walls [7]. However, the oil yield of kenaf seed that roasted for $3 \mathrm{~min}$ decreased to $20.17 \%$. The reduction of oil yield maybe due to that some of the kenaf seeds started to be overcooked and burnt after $3 \mathrm{~min}$ of microwave roasting, and this affected the oil content in the seeds.

\subsection{Peroxide Value (PV)}

The $P V$ for the unroasted sample was $1.50 \mathrm{meq}$ $\mathrm{O}_{2} / \mathrm{kg}$ of oil and increased to $1.99 \mathrm{meq} \mathrm{O}_{2} / \mathrm{kg}$ of oil for the 1 min sample. Then, there was a sudden decrease in $P V$ for the 2 min sample, which only had $0.99 \mathrm{meq}$ $\mathrm{O}_{2} / \mathrm{kg}$ of oil. However, the $P V$ for $3 \mathrm{~min}$ sample increased to $1.98 \mathrm{meq} \mathrm{O}_{2} / \mathrm{kg}$ of oil. The seed oil from 2 min sample had the lowest $P V$ among all the samples. All the samples were significantly different from each other $(P<0.05)$.

The $P V$ for samples of $1 \mathrm{~min}$ and $3 \mathrm{~min}$ of roasting time increased if compared to the unroasted sample. This was because the hydroperoxides in kenaf seed oil were relatively stable. However, the $P V$ started to decrease when the heating time reached $2 \mathrm{~min}$, as the hydroperoxides in the oil had become unstable. Moreover, it also caused the decrease of $P V$ that the rate of hydroperoxide decomposition exceeded the rate of hydroperoxide formation.

Table 1 Effects of microwave roasting on quality of kenaf seed oil.

\begin{tabular}{lllll}
\hline \multirow{2}{*}{ Analysis } & \multicolumn{3}{c}{ Time of microwave roasting (min) } \\
\cline { 2 - 5 } & 0 & 1 & 2 & 3 \\
\hline Oil yield (\%) & $20.37 \pm 0.03^{\mathrm{b}}$ & $20.42 \pm 0.14^{\mathrm{b}}$ & $22.05 \pm 0.06^{\mathrm{a}}$ & $20.17 \pm 0.08^{\mathrm{b}}$ \\
$P V\left(\mathrm{meq} \mathrm{O}_{2} / \mathrm{kg}\right.$ of oil) & $1.50 \pm 0.01^{\mathrm{b}}$ & $1.99 \pm 0.01^{\mathrm{a}}$ & $0.99 \pm 0.01^{\mathrm{c}}$ & $1.98 \pm 0.01^{\mathrm{a}}$ \\
$A V$ & $4.49 \pm 0.02^{\mathrm{a}}$ & $2.92 \pm 0.01^{\mathrm{d}}$ & $3.15 \pm 0.01^{\mathrm{b}}$ & $3.01 \pm 0.01^{\mathrm{c}}$ \\
TOTOX & $7.47 \pm 0.01^{\mathrm{a}}$ & $6.91 \pm 0.01^{\mathrm{c}}$ & $5.13 \pm 0.01^{\mathrm{d}}$ & $6.98 \pm 0.03^{\mathrm{b}}$ \\
$I V(\mathrm{~g} \mathrm{of} \mathrm{I} / 100 \mathrm{~g}$ oil) & $87.92 \pm 0.07^{\mathrm{a}}$ & $86.65 \pm 0.03^{\mathrm{b}}$ & $86.23 \pm 0.03^{\mathrm{c}}$ & $80.34 \pm 0.09^{\mathrm{d}}$ \\
FFA $(\mathrm{mg} \mathrm{KOH} / 100 \mathrm{~g}$ oil $)$ & $3.02 \pm 0.02^{\mathrm{d}}$ & $3.35 \pm 0.04^{\mathrm{c}}$ & $4.42 \pm 0.02^{\mathrm{b}}$ & $4.69 \pm 0.03^{\mathrm{a}}$ \\
\hline
\end{tabular}

${ }^{\mathrm{a}-\mathrm{d}}$ Means values with different letters in the rows are significantly different $(P<0.05)$; values are represented in means \pm standard deviation $(n=4)$. 


\subsection{P-Anisidine Value (AV) and Total Oxidation Value (TOTOX)}

The $P V, A V$ and TOTOX are important criteria in determining the quality of oil. The unroasted sample had the highest $A V$ (4.49), followed by sample roasted for $2 \min$ (3.15), $3 \mathrm{~min}$ (3.01) and $1 \mathrm{~min}$ (2.92), respectively. There was significant difference $(P<$ 0.05 ) among the four samples.

$A V$ in the roasted kenaf seed oil decreased if compared to the unroasted kenaf seed oil, as the aldehydes in oil continually increased. Aldehydes are decay products of hydroperoxides from primary oxidation and hydroperoxides in the oil become unstable after prolonged heating, thus, the $A V$ of oil decreased.

TOTOX indicates the total oxidation level of oil sample by using both $P V$ and $A V$. Samples roasted for 2 min had the lowest TOTOX (5.13), followed by 1 min (6.91), $3 \mathrm{~min}$ (6.98) and the unroasted sample (7.47), respectively. It had clearly shown that microwave pre-treatment had a significant effect on the TOTOX of kenaf seed oil. The samples that undergo microwave pre-treatment had lower TOTOX compared to the unroasted sample. Overall, 2 min oil sample tended to have better quality if compared to other oil samples, as it had the lowest TOTOX.

\subsection{Iodine Value (IV)}

As roasting time increased, the $I V$ of extracted oils decreased. The $I V$ for the unroasted oil sample was $87.92 \mathrm{~g}$ of $\mathrm{I}_{2} / 100 \mathrm{~g}$ oil and gradually decreased to $80.34 \mathrm{~g}_{\mathrm{g}} \mathrm{I}_{2} / 100 \mathrm{~g}$ oil for the $3 \mathrm{~min}$ oil sample. The $I V$ of the four samples were significantly different $(P<$ $0.05)$.

During roasting, $I V$ is often used as a rough criterion of oil stability. This is due to the more unsaturated oils are unstable to thermal oxidation. Thus, a decrease in $I V$ is due to the decrease in the number of double bonds for the fatty acids. Moreover, the decrease in $I V$ may happen due to the reductions in the number of unsaturation sites of oil as a result of oxidation, polymerization or breakage of the long chain fatty acids.

\subsection{Free Fatty Acids Value (FFA)}

The FFA for the unroasted oil sample was $3.02 \mathrm{mg}$ $\mathrm{KOH} / 100 \mathrm{~g}$ oil, and then gradually increased to 3.35 $\mathrm{mg} \mathrm{KOH} / 100 \mathrm{~g}$ oil $(1 \mathrm{~min}), 4.42 \mathrm{mg} \mathrm{KOH} / 100 \mathrm{~g}$ oil (2 $\mathrm{min}$ ) and $4.69 \mathrm{mg} \mathrm{KOH} / 100 \mathrm{~g}$ oil $(3 \mathrm{~min}$ ), respectively. The FFA increased significantly $(P<$ $0.05)$ as the roasting time increased. The increase in FFA of oil might be caused by the hydrolysis of triacylglycerols (TAG) by microwaves to produce free fatty acids.

\subsection{Fatty Acid Composition}

Fatty acid composition of unroasted and roasted kenaf seed oils are given in Table 2. The principal fatty acid components of unroasted kenaf seed oil were palmitic (C16:0), oleic (C18:1) and linoleic acid (C18:2), which were $21.8 \%, 24.8 \%$ and $48.4 \%$, respectively. Linoleic acid was the most fatty acid components that can be found in kenaf seed oil, followed by oleic acid and palmitic acid. Similarly, Mohamed et al. [4] also reported that kenaf seed oil consist of the highest percentage of linoleic acid, followed by oleic acid and palmitic acid, which were $45.9 \%, 29.2 \%$ and $20.1 \%$, respectively.

There was a little change in the fatty acid composition of the kenaf seed oils when the seeds were roasted in microwave oven for 1, 2 and $3 \mathrm{~min}$. Microwave roasting had greater effect on oleic and linoleic acids if compared to palmitic and stearic acids in kenaf seed oil. The longer the roasting time was, the higher the percentage of oleic acid was. This was because linoleic acid has been broken down into oleic acid. The oleic acid increased up to $24.9 \%$ during 3 min of microwave roasting. However, the linoleic acid decreased significantly with the longer roasting time $(P<0.05)$. In Table 2, it had clearly shown that the percentage of the linoleic acid decreased from $48.4 \%$ 
Table 2 Effects of microwave roasting on fatty acid composition (\%) of kenaf seed oil.

\begin{tabular}{lllll}
\hline \multirow{2}{*}{ Fatty acid } & \multicolumn{3}{c}{ Time of microwave roasting (min) } \\
\cline { 2 - 5 } & 0 & 1 & 2 & 3 \\
\hline Palmitic acid (C16:0) & $21.8 \pm 0.4^{\mathrm{a}}$ & $21.8 \pm 0.3^{\mathrm{a}}$ & $21.9 \pm 0.2^{\mathrm{a}}$ & $21.9 \pm 0.1^{\mathrm{a}}$ \\
Palmitoleic acid (C16:1) & $0.5 \pm 0.0^{\mathrm{b}}$ & $0.5 \pm 0.0^{\mathrm{b}}$ & $0.6 \pm 0.0^{\mathrm{a}}$ & $0.5 \pm 0.0^{\mathrm{b}}$ \\
Stearic acid (C18:0) & $4.2 \pm 0.2^{\mathrm{a}}$ & $4.3 \pm 0.2^{\mathrm{a}}$ & $4.3 \pm 0.1^{\mathrm{a}}$ & $4.3 \pm 0.1^{\mathrm{a}}$ \\
Oleic acid (C18:1) & $24.8 \pm 0.6^{\mathrm{c}}$ & $25.5 \pm 0.3^{\mathrm{b}, \mathrm{c}}$ & $25.8 \pm 0.2^{\mathrm{b}}$ & $26.4 \pm 0.1^{\mathrm{a}}$ \\
Linoleic acid (C18:2) & $48.4 \pm 0.4^{\mathrm{a}}$ & $47.6 \pm 0.1^{\mathrm{b}}$ & $47.1 \pm 0.2^{\mathrm{b}}$ & $46.5 \pm 0.1^{\mathrm{c}}$ \\
Linolenic acid (C18:3) & $0.3 \pm 0.0^{\mathrm{a}}$ & $0.3 \pm 0.0^{\mathrm{a}}$ & $0.3 \pm 0.1^{\mathrm{a}}$ & $0.3 \pm 0.1^{\mathrm{a}}$ \\
SAT & 26.0 & 26.1 & 26.2 & 26.2 \\
MONO & 25.3 & 26.0 & 26.4 & 26.9 \\
PUFA & 48.7 & 47.9 & 47.4 & 46.8 \\
\hline
\end{tabular}

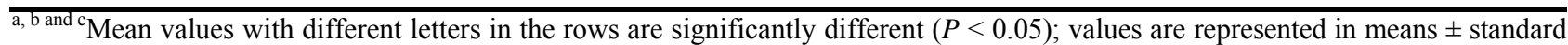
deviation $(n=4)$; SAT: saturated fatty acids; MONO: monounsaturated fatty acid; POLY: polyunsaturated fatty acids.

Table 3 Effects of microwave roasting on tocopherol compositions (mg/100 g oil) of kenaf seed oil.

\begin{tabular}{lllll}
\hline Tocopherol compositions & \multicolumn{4}{c}{ Time of microwave roasting (min) } \\
\cline { 2 - 5 } (mg/100 g oil) & 0 & 1 & 2 & 3 \\
\hline$\alpha$-tocopherol & $6.8 \pm 0.4^{\mathrm{a}}$ & $6.4 \pm 0.3^{\mathrm{a}}$ & $5.3 \pm 0.4^{\mathrm{b}}$ & $5.2 \pm 0.2^{\mathrm{b}}$ \\
$\delta$-tocopherol & $3.0 \pm 0.1^{\mathrm{a}}$ & $2.3 \pm 0.1^{\mathrm{b}}$ & $2.1 \pm 0.1^{\mathrm{b}}$ & $1.7 \pm 0.1^{\mathrm{c}}$ \\
$\gamma$-tocopherol & $29.0 \pm 2.6^{\mathrm{a}}$ & $28.2 \pm 1.4^{\mathrm{a}, \mathrm{b}}$ & $24.5 \pm 1.9^{\mathrm{b}, \mathrm{c}}$ & $23.3 \pm 1.3^{\mathrm{c}}$ \\
Total tocopherol & 38.8 & 36.9 & 31.9 & 30.2 \\
\hline
\end{tabular}

a, b and ${ }^{c}$ Means values with different letters in the rows are significantly different $(P<0.05)$; values are represented in means \pm standard deviation $(n=4)$.

(unroasted) to $46.5 \%$ (3 $\mathrm{min}$ ). However, microwave roasting caused no significant difference in the palmitic and stearic acids $(P>0.05)$.

\subsection{Tocopherol Composition}

The changes in the content of $\alpha-, \delta$ - and $\gamma$ tocopherol in kenaf seed oils with microwave roasting time is summarized in Table 3. The unroasted kenaf seed oil sample was found to contain $6.8 \mathrm{mg}$ of $\alpha$-tocopherol $/ 100 \mathrm{~g}$ oil, $3.0 \mathrm{mg}$ of $\delta$-tocopherol/100 g oil and $29.0 \mathrm{mg}$ of $\gamma$-tocopherol/100 g oil, respectively. However, the tocopherol composition in kenaf seed oil decreased significantly $(P<0.05)$ during microwave roasting. The level of $\alpha$-tocopherol decreased to $6.4 \mathrm{mg} / 100 \mathrm{~g}$ oil ( $1 \mathrm{~min}), 5.3 \mathrm{mg} / 100 \mathrm{~g}$ oil ( $2 \mathrm{~min}$ ) and $5.2 \mathrm{mg} / 100$ $\mathrm{g}$ oil (3 $\mathrm{min})$, respectively. In the case of $\delta$-tocopherol, it showed a trend of decrease from the unroasted sample to $2.3 \mathrm{mg} / 100 \mathrm{~g}$ oil for $1 \mathrm{~min}, 2.1$ $\mathrm{mg} / 100 \mathrm{~g}$ oil for $2 \mathrm{~min}$ and $1.7 \mathrm{mg} / 100 \mathrm{~g}$ oil for 3 min oil sample. Furthermore, $\gamma$-tocopherol in kenaf seed oil decreased slightly to $28.2 \mathrm{mg} / 100 \mathrm{~g}$ oil (1 $\mathrm{min}), 24.5 \mathrm{mg} / 100 \mathrm{~g}$ oil $(2 \mathrm{~min})$ and $23.3 \mathrm{mg} / 100 \mathrm{~g}$ oil (3 min), respectively. Besides, the most abundant tocopherol found in kenaf seed oil was $\gamma$-tocopherol, followed by $\alpha$-tocopherol and $\delta$-tocopherol which had the lowest concentration. The total tocopherol content for unroasted sample was $38.8 \mathrm{mg} / 100 \mathrm{~g}$ oil, then decreased to $36.9 \mathrm{mg} / 100 \mathrm{~g}$ oil $(1 \mathrm{~min}), 31.9$ $\mathrm{mg} / 100 \mathrm{~g}$ oil (2 min) and $30.2 \mathrm{mg} / 100 \mathrm{~g}$ oil (3 min), respectively.

The reduction of tocopherol content in kenaf seed oil might be the result of thermal degradation or microstructural changes in seeds that happen due to the elevated temperature of roasting. Therefore, the decrease in the tocopherol composition was attributed to the breakage of phosphates and phospholipids bonds in oil by the microwave heat [4]. These results suggested that changes of tocopherol contents in the oils were dependent on roasting time. 


\subsection{Antioxidant Activities}

The effects of microwave roasting on antioxidant activities of kenaf seed oil are shown in Table 4. The antioxidant activities of kenaf seed oils were measured by DPPH radical scavenging capacity assay, TPC and TFC. Microwave pre-treatment caused an increase in terms of antioxidant activities of kenaf seed oils. In DPPH test, the unroasted kenaf seed oil contained $208.80 \mathrm{mg}$ trolox/100 $\mathrm{g}$ oil, and it showed an increment to $461.30 \mathrm{mg}$ trolox $/ 100 \mathrm{~g}$ oil after roasted for $1 \mathrm{~min}, 878.30 \mathrm{mg}$ trolox/100 $\mathrm{g}$ oil after $2 \mathrm{~min}$ and $1,011.50 \mathrm{mg}$ trolox/100 $\mathrm{g}$ oil after $3 \mathrm{~min}$, respectively. The TPC of kenaf seed oil increased gradually from $140.33 \mathrm{mg}$ gallic acid/100 g oil (unroasted) to 172.27 $\mathrm{mg}$ gallic acid/100 g oil, $174.13 \mathrm{mg}$ gallic acid/100 g oil and $176.14 \mathrm{mg}$ gallic acid/100 $\mathrm{g}$ oil for roasted kenaf seed oil $1 \mathrm{~min}, 2 \mathrm{~min}$ and $3 \mathrm{~min}$, respectively. A similar trend was observed for TFC that increased to $3,043 \mathrm{mg}$ catechin/100 $\mathrm{g}$ oil in $3 \mathrm{~min}$ oil sample if compared to $2,672 \mathrm{mg}$ catechin/100 $\mathrm{g}$ oil that found in the unroasted oil. The antioxidant activities of kenaf seed oil increased significantly $(P<0.05)$ with the longer time of microwave roasting.

Total antioxidant activity reflects presence of naturally and neo-formed antioxidant constituents in oils obtained from the unroasted and roasted kenaf seeds. The increase might be due to that phenolic compounds were able to pass into the oil phase better during microwave roasting, as high temperature caused chemical alteration of phenolics. The increase of total antioxidant capacity is probably caused by the release of phenolic compounds from bound structures or chemical alteration of phenolics at higher temperatures. Besides, the increase of total antioxidant capacity of kenaf seed oil might be attributed to the Maillard reaction products (MRPs) formed during microwave roasting. Similarly, Durmaz and Gokmen [16] reported that MRPs formed during roasting process might have contributed to the increase in antioxidant activities.

\subsection{Colour Intensity}

The colour intensity of unroasted and roasted kenaf seed oils was measured in terms of $L^{*}$ (lightness), $a^{*}$ (redness) and $b^{*}$ (yellowness). The results are summarized in Table 5. The table showed that by increasing microwave roasting time, oil lightness $\left(L^{*}\right)$ and yellowness $\left(b^{*}\right)$ increased. The $L^{*}$ values for unroasted oil sample was 12.14 and increased to 16.98 , 17.73 and 21.27 for 1,2 and 3 min oil sample, respectively. On the other hand, the $b^{*}$ values of kenaf seed oil showed an increment from 16.93 (unroasted)

Table 4 Effects of microwave roasting on antioxidant activities of kenaf seed oil.

\begin{tabular}{lllll}
\hline \multirow{2}{*}{ Antioxidant activities } & \multicolumn{3}{c}{ Time of microwave roasting (min) } \\
\cline { 2 - 5 } & 0 & 1 & 2 & 3 \\
\hline DPPH (mg trolox/100 g oil) & $208.80 \pm 7.20^{\mathrm{d}}$ & $461.30 \pm 9.40^{\mathrm{c}}$ & $878.30 \pm 137.30^{\mathrm{b}}$ & $1,011.50 \pm 83.80^{\mathrm{a}}$ \\
TPC (mg gallic acid/100 g oil) & $140.33 \pm 0.27^{\mathrm{d}}$ & $172.27 \pm 0.10^{\mathrm{c}}$ & $174.13 \pm 0.09^{\mathrm{b}}$ & $176.14 \pm 0.36^{\mathrm{a}}$ \\
TFC (mg catechin/100 g oil) & $2,672.00 \pm 14.10^{\mathrm{d}}$ & $2,753.00 \pm 21.60^{\mathrm{c}}$ & $2,843.00 \pm 34.00^{\mathrm{b}}$ & $3,043.00 \pm 21.60^{\mathrm{a}}$ \\
\hline a-d Means values with different letters in the rows are significantly different $(P<0.05) ;$ values are represented in means \pm standard \\
deviation $(n=4)$.
\end{tabular}

Table 5 Effects of microwave roasting on the colour of kenaf seed oil.

\begin{tabular}{lllll}
\hline \multirow{2}{*}{ Colour values } & \multicolumn{3}{c}{ Time of microwave roasting (min) } \\
\cline { 2 - 5 } & 0 & 1 & 2 & 3 \\
\hline$L^{*}$ & $12.14 \pm 0.08^{\mathrm{d}}$ & $16.98 \pm 0.18^{\mathrm{c}}$ & $17.73 \pm 0.07^{\mathrm{b}}$ & $21.27 \pm 0.08^{\mathrm{a}}$ \\
$a^{*}$ & $7.17 \pm 0.03^{\mathrm{b}}$ & $5.51 \pm 0.06^{\mathrm{d}}$ & $5.84 \pm 0.05^{\mathrm{c}}$ & $10.48 \pm 0.08^{\mathrm{a}}$ \\
$b^{*}$ & $16.93 \pm 0.05^{\mathrm{c}}$ & $17.21 \pm 0.15^{\mathrm{c}}$ & $19.49 \pm 0.06^{\mathrm{b}}$ & $29.89 \pm 0.14^{\mathrm{a}}$ \\
\hline
\end{tabular}

${ }_{\mathrm{a}-\mathrm{d}}$ Means values with different letters in the rows are significantly different $(P<0.05)$; values are represented in means \pm standard deviation $(n=4)$. 
to $17.21(1 \mathrm{~min}), 19.49(2 \mathrm{~min})$ and $29.89(3 \mathrm{~min})$, respectively. However, microwave roasting caused a fluctuation of $a^{*}$ values of kenaf seed oils. The redness of kenaf seed oil decreased from 7.17 (unroasted) to 5.51 and 5.84 for $2 \mathrm{~min}$ and $3 \mathrm{~min}$ oil samples, respectively. There was a sudden increase to 10.48 when the roasting time reached 3 min. The colour intensity of roasted and unroasted kenaf seed oils were significantly different $(P<0.05)$.

Kenaf seed oils that obtained from roasted seeds were reported to have darker colour in term of yellowness $\left(b^{*}\right)$ if compared to the oil from unroasted seeds. This is caused by the formation of MRPs during microwave pre-treament. The darker colour found in oil from roasted seeds is most probable compared to oil from raw seeds because of the passage of MRPs formed during roasting [17]. Besides, the increase of colour intensity in kenaf seed oils is attributed to the accumulation of nonvolatile decomposition products, such as oxidized triacylglycerols and free fatty acids due to the high temperature during microwave pre-treatment [18].

\section{Conclusions}

Microwave pre-treatment on kenaf seeds did affect the quality of oils. The oil quality of roasted kenaf seeds was better compared to the unroasted oil sample. Microwave pre-treatment caused an increment in oil yield, of which the highest yield was obtained for kenaf seeds that were roasted for $2 \min (22.05 \%)$. Moreover, oxidative stability of kenaf seed oils substantially was improved after microwave pre-treatment. The increase of total antioxidant capacity is probably caused by the release of phenolic compounds from bound structures or chemical alteration of phenolics at higher temperatures. Besides, the increase of total antioxidant capacity of kenaf seed oil might be attributed to MRPs formed during microwave roasting.

\section{Acknowledgments}

Financial support of this work by internal funding from UCSI University is gratefully acknowledged.

\section{References}

[1] LeMahieu, P. J., Oplinger, E. S., and Putnam, D. H. 2003. "Kenaf." Alternative Field Crops Manual. Accessed September 15, 2014. http://www.corn.agronomy.wisc.edu/FISC/Alternatives/K enaf.htm.Perusal on 15/3/2007.

[2] Foo, J. B., Yazan, L. S., Chan, K. W., Tahir, P. M., and Ismail, M. 2011. "Kenaf Seed Oil from Supercritical Carbon Dioxide Fluid Extraction Induced G1 Phase Cell Cycle Arrest and Apoptosis in Leukemia Cells." Afr. J. Biochem. 10 (27): 5389-97.

[3] Coetzeea, R., Labuschagnea, M. T., and Hugob, A. 2008. "Fatty Acid and Oil Variation in Seed from Kenaf (Hibiscus cannabinus L.)." Ind. Crops Prod. 27 (1): 104-9.

[4] Mohamed, A., Bhardwaj, H., Hamama, A., and Webber, C. 1995. "Chemical Composition of Kenaf (Hibiscus cannabinus L.) Seed Oil.” Ind. Crops Prod. 4 (3): 157-65.

[5] Nyam, K. L., Tan, C. P., Lai, O. M., Long, K., and Che Man, Y. B. 2009. "Physicochemical Properties and Bioactive Compounds of Selected Seed Oils." LWT-Food Sci. Technol. 42 (8): 1396-403.

[6] Anjum, F., Anwar, F., Jamil, A., and Iqbal, M. 2006. "Microwave Roasting Effects on the Physiochemical Composition and Oxidative Stability of Sunflower Seed Oil.” J. Am. Oil Chem. Soc. 83 (9): 777-84.

[7] Uquiche, E., Jeréz, M., and Ortiz, J. 2008. "Effect of Pre-treatment with Microwaves on Mechanical Extraction Yield and Quality of Vegetable Oil from Chilean Hazelnuts (Gevuina avellana Mol.)." Innov. Food Sci. Emerging Technol. 9 (4): 495-500.

[8] Megahed, M. G. 2011. "Effect of Microwave Heating of Linseed Oil on the Formation of Primary and Secondary Oxidation Products." Agric. Biol. J. North Am. 2 (4): 673-9.

[9] Veldsink, J. W., Muuse, B. G., Meijer, M. M. T., Cuperus, F. P., Van de Sande, R. L. K. M., and Van Putte, K. P. A. M. 1999. "Heat Pre-treatment of Oilseeds: Effect on Oil Quality." Fett/Lipid 101 (7): 244-8.

[10] Ng, S. K., Jessie, L. L. Y., Tan, C. P., Long, K., and Nyam, K. L. 2013. "Effect of Accelerated Storage on Microencapsulated Kenaf Seed Oil." J. Am. Oil Chem. Soc. 90 (7): 1023-9. 
[11] American Oil Chemists' Society (AOCS). 2007. Official Methods and Recommended Practices of the American Oil Chemists' Society. Champaign, USA: AOCS.

[12] O'Connor, C. J., Lal, S. N. D., and Eyres, L. 2007. Handbook of Australasian Edible Oils, Oils and Fats. Auckland, New Zealand: NZIC.

[13] Liu, Y. G. 2005. "Diallel and Stability Analysis of Kenaf (Hibiscus cannabinus L.) in South Africa.” Ph.D. thesis, University of the Free State, South Africa.

[14] Nyam, K. L., Wong, M. M., Long, K., and Tan, C. P. 2013. "Oxidative Stability of Sunflower Oils Supplemented with Kenaf Seeds Extract, Roselle Seeds Extract and Roselle Extract, Respectively under Accelerated Storage." Inter. Food Res. J. 20 (2): 645-51.

[15] Sara, R., Tan, C. P., Long, K., and Nyam, K. L. 2013.
"Quality Changes and Antioxidant Properties of Microencapsulated Kenaf (Hibiscus cannabinus L.) Seed Oil during Accelerated Storage." J. Am. Oil Chem. Soc. 90 (12): 1859-67.

[16] Durmaz, G., and Gokmen, V. 2011. "Changes in Oxidative Stability, Antioxidant Capacity and Phytochemical Composition of Pistacia terebinthus Oil with Roasting." Food Chem. 128 (2): 410-4.

[17] Kim, I. H., Kim, C. J., You, M. J., Lee, K. W., Kim, C. T., Chung, S. H., and Tae, B. S. 2002. "Effect of Roasting Temperature and Time on the Chemical Composition of Rice Germ Oil.” J. Oil Chem. Soc. 79 (5): 413-8.

[18] Hassanein, M. M., El-Shami, S. M., Al-Mallah, M. H. 2003. "Changes Occurring in Vegetable Oils Composition due to Microwave Heating." Grasas $y$ Aceites 54 (4): 343-9. 